\title{
Age, physical inactivity, obesity, health conditions, and health-related quality of life among patients receiving conservative management for musculoskeletal disorders
}

\author{
This article was published in the following Dove Press journal: \\ Clinical Interventions in Aging \\ 10 July 2014 \\ Number of times this article has been viewed
}

\author{
Steven M McPhail ${ }^{1,2}$ \\ Mandy Schippers ${ }^{1,2}$ \\ Alison L Marshall ${ }^{2}$ \\ 'Centre for Functioning and Health \\ Research, Metro South Health, \\ Brisbane, QLD, Australia; ${ }^{2}$ Institute \\ of Health and Biomedical Innovation, \\ and School of Public Health and \\ Social Work, Queensland University \\ of Technology, Brisbane, QLD, \\ Australia
}

\begin{abstract}
Background: Musculoskeletal conditions and insufficient physical activity have substantial personal and economic costs among contemporary aging societies. This study examined the age distribution, comorbid health conditions, body mass index (BMI), self-reported physical activity levels, and health-related quality of life of patients accessing ambulatory hospital clinics for musculoskeletal disorders. The study also investigated whether comorbidity, BMI, and self-reported physical activity were associated with patients' health-related quality of life after adjusting for age as a potential confounder.
\end{abstract}

Methods: A cross-sectional survey was undertaken in three ambulatory hospital clinics for musculoskeletal disorders. Participants $(n=224)$ reported their reason for referral, age, comorbid health conditions, BMI, physical activity levels (Active Australia Survey), and health-related quality of life (EQ-5D). Descriptive statistics and linear modeling were used to examine the associations between age, comorbidity, BMI, intensity and duration of physical activity, and health-related quality of life.

Results: The majority of patients ( $\mathrm{n}=115,51.3 \%$ ) reported two or more comorbidities. In addition to other musculoskeletal conditions, common comorbidities included depression $(n=41$, $18.3 \%)$, hypertension ( $n=40,17.9 \%)$, and diabetes $(n=39,17.4 \%)$. Approximately one-half of participants $(\mathrm{n}=110,49.1 \%)$ self-reported insufficient physical activity to meet minimum recommended guidelines and $150(67.0 \%)$ were overweight $(n=56,23.2 \%)$, obese $(n=64,28.6 \%)$, severely obese $(n=16,7.1 \%)$, or very severely obese $(n=14,6.3 \%)$, with a higher proportion of older patients affected. A generalized linear model indicated that, after adjusting for age, selfreported physical activity was positively associated $(z=4.22, P<0.001)$, and comorbidities were negatively associated $(z=-2.67, P<0.01)$ with patients' health-related quality of life.

Conclusion: Older patients were more frequently affected by undesirable clinical attributes of comorbidity, obesity, and physical inactivity. However, findings from this investigation are compelling for the care of patients of all ages. Potential integration of physical activity behavior change or other effective lifestyle interventions into models of care for patients with musculoskeletal disorders is worthy of further investigation.

Keywords: aging, comorbidity, physical activity, orthopedic, sedentary, overweight

\section{Introduction}

The increasing prevalence, health burden, and economic cost of chronic musculoskeletal disorders over recent decades have resulted in their identification as a key health concern for contemporary aging societies. ${ }^{1-7}$ The estimated economic cost of musculoskeletal disorders in the United States was $7.4 \%$ of the nation's gross domestic product,
Centre for Funct Steven M McPhail Research, c/o ABIOS/CFAHR, Princess Alexandra Hospital Campus, Corner of Ipswich Road and Cornwall Street, Woolongabba, QLD 4102, Australia Email steven.mcphail@health.qld.gov.au 
or approaching $\$ 950$ billion annually (2006). ${ }^{8}$ In addition, concerning personal and economic costs of musculoskeletal disorders have been reported among other nations. ${ }^{5-7,9,10}$ This has occurred while the proportion of the population meeting minimum recommended physical activity guidelines has decreased, and child and adult obesity levels have increased internationally. ${ }^{11-20}$

Empirical evidence suggests that the increasing burden of chronic musculoskeletal disorders among increasingly sedentary populations is not a coincidence. ${ }^{21-26}$ Musculoskeletal disorders are prevalent among sedentary populations, even though insufficient physical activity is a modifiable risk factor for premature mortality. ${ }^{27-33}$ Insufficient physical activity is associated with a range of negative health outcomes that can have increasing prevalence with aging, including heart disease, diabetes, and musculoskeletal disorders, as well as depression. ${ }^{31,33-35}$ The World Health Organization has identified physical inactivity as the fourth leading risk factor for mortality globally. ${ }^{27}$ In addition to negative personal health impacts, physical inactivity places a heavy financial burden on economies worldwide. For example, the annual cost of physical inactivity to the United States economy was estimated at US $\$ 13.8$ billion in $2008 .{ }^{36}$ Despite Australia having a much smaller population than the United States, the cost of physical inactivity to the Australian health care system in 2007 was an avoidable AU\$1.5 billion per year, ${ }^{37}$ representing a substantial economic burden to the Australian society and demonstrating that this problem is not isolated by geographical region.

There are a range of benefits associated with increasing physical activity. Immediate gains include improved musculoskeletal and mental health as well as cardiovascular and respiratory benefits. ${ }^{31,38}$ Medium- and longer-term benefits are wide-ranging. ${ }^{28-35}$ Physical activity may reduce the severity of existing health conditions and prevent a range of further comorbidities. ${ }^{28-35}$ Increasing or maintaining physical activity levels and physical functioning can also reduce the risk of being impacted by physical debility and falls associated with aging. ${ }^{39-42}$

From a health service perspective, people with musculoskeletal disorders are an important clinical group that are likely to benefit from physical activity, but who may require additional support to become physically active. ${ }^{34,35}$ Musculoskeletal disorders cause pain and contribute to reduced mobility and impaired health-related quality of life. ${ }^{35,43}$ Chronic musculoskeletal disorders and physical inactivity have been associated with other conditions, such as obesity and depression. ${ }^{34}$ The interaction between patients and health professionals in clinical settings may prove a useful opportunity to link inactive patients with positive physical activity behavior change interventions. ${ }^{44}$ While it is likely that people accessing ambulatory clinical services for nonsurgical treatment of musculoskeletal disorders would obtain health benefits from increasing their physical activity levels, a range of important research questions in this field currently remain unanswered. For potential investment in physical activity behavior change interventions to be justified and appropriately targeted in these clinical settings, it is important to understand the health profile of patients accessing these services.

This investigation had three objectives to be investigated among people receiving nonsurgical interventions for musculoskeletal conditions affecting any body region. The first objective was to examine the age distribution, comorbid health conditions, body mass index (BMI), and self-reported physical activity levels among patients accessing (nonsurgical) ambulatory hospital clinics for musculoskeletal disorders. The second objective was to describe the health-related quality of life profile of this sample. The third objective was to investigate whether comorbidity, BMI, and self-reported physical activity were associated with patients' overall health-related quality of life (after adjusting for age as a potential confounder).

\section{Methods \\ Design}

A cross-sectional survey investigation utilizing a customdesigned quantitative questionnaire (including standardized self-reported measures of physical activity and healthrelated quality of life) at a single assessment point was undertaken.

\section{Participants and setting}

A total of 296 community-dwelling adult patients accessing ambulatory hospital services for nonsurgical treatment of one or more musculoskeletal disorders were invited to participate between January and March 2012. This was a convenience cross-sectional sample of patients accessing the participating clinics. An additional 1-month post-recruitment closure period was permitted for the return of any questionnaires that had been completed but not yet returned. The ambulatory hospital services included a musculoskeletal physical therapy outpatient clinic, a multidisciplinary (physical therapy, nutrition and dietetics, psychology, occupational therapy) service for spinal pain, and a musculoskeletal outpatient aquatic physical therapy clinic. These clinics were selected because they included a broad cross-section of community-dwelling 
individuals with musculoskeletal conditions receiving conservative (nonsurgical) interventions.

It is usual practice for patients attending these clinics to receive therapy programs according to their individual musculoskeletal condition and other circumstances, including their response to initial treatment and perceived potential to receive benefit from further intervention. The volume of intervention and frequency of clinic appointments are not rigidly predetermined according to the type of referral or presenting condition. Participation in this study did not affect patients' routine clinical care, and the amount of therapy that individuals received (before or after completing the questionnaire) was not within the scope of this investigation.

\section{Ethics statement}

This investigation was approved by the Metro South Health (Brisbane, QLD, Australia) Research Ethics Committee and the Queensland University of Technology (Brisbane, QLD, Australia) Human Research Ethics Committee. Participation or nonparticipation in this research investigation were voluntary and did not influence the care offered to or received by patients. Patients provided informed consent before participation in the study.

\section{Outcomes}

The questionnaire contained items about demographic and clinical information including age; sex; weight and height (used to calculate BMI); primary reason for referral to the clinic; comorbid health conditions; self-reported physical activity levels (measured with the Active Australia Survey ${ }^{45}$ ); and health-related quality of life, measured with the EQ-5D instrument. ${ }^{46}$

The Active Australia Survey required participants to report the number of weekly occurrences and total duration of: continuous walking for at least 10 minutes; vigorous gardening or heavy work around the yard; vigorous physical activity (for example, jogging or cycling); and other moderate physical activities (for example, swimming or social tennis). ${ }^{45}$ The number and duration of activities reported may include any type of physical activity. The physical activity reported is classified into walking, moderate activity, or vigorous activity, including duration and number of activities per week in each of the categories. ${ }^{45}$ For determining whether a respondent was sufficiently physically active to meet minimum recommended guidelines for health benefits, time spent undertaking vigorous activity was assigned a double weighting. ${ }^{45}$ Sufficient physical activity is calculated as the accumulation of at least five sessions and 150 minutes of moderate physical activity (or equivalent vigorous activity) per week. ${ }^{45}$ This instrument was developed and validated as part of an Australian government initiative to assist in the collection of standardized data for physical activity measurement among Australian adults. ${ }^{45}$ The Australian Institute of Health and Welfare established an expert working group on physical activity measurement to develop the questionnaire content. ${ }^{45}$ This group examined the issues surrounding measurement of physical activity, reviewed existing physical activity measures, and undertook related research and consultation before identifying data elements necessary for physical activity measurement. ${ }^{45}$ The Active Australia Survey has been used in nationwide and state-based government surveys in Australia and has exhibited good reliability, face validity, criterion validity, and respondent acceptability. ${ }^{45,47}$

The EQ-5D is among the most widely used instruments internationally for the evaluation of health-related quality of life among older adults in clinical and research settings. ${ }^{46-52}$ This generic health-related quality of life questionnaire includes the five domains of mobility, personal care, usual activities, pain/discomfort, and anxiety/depression. In each domain, respondents indicate that they experience no problems, some/moderate problems, or extreme problems/inability. The instrument also includes a 101-point vertical visual analog scale (EQ-VAS), where $0(0 \mathrm{~cm})$ and $100(20 \mathrm{~cm})$ represent the worst and best imaginable health state, respectively. ${ }^{46}$ Responses from the five domains can be converted to a single summary score, where death and full health are represented by 0.00 and 1.00 , respectively; ${ }^{.3,54}$ this is known as a multiattribute utility score. The EQ-5D has demonstrated favorable validity, ${ }^{49-52,55,56}$ reliability, ${ }^{48-51}$ and responsiveness ${ }^{49,51,52,57}$ across a range of adult populations. ${ }^{48-52,55-57}$

The investigators considered it plausible that some inaccuracies may be present using self-report questionnaires (particularly for physical activity levels) in comparison to objective monitoring or a suite of clinical tests for common conditions. However, the decision to select the aforementioned outcome measures for this investigation was guided by several factors. First, survey completion had the pragmatic advantage of being more efficient and less invasive than pathology testing or objective physical activity monitoring, which would likely have yielded a lower participation rate and higher chance of sampling bias than questionnaire-based assessments. Second, the aforementioned instruments permitted the investigators to consider whether data from this sample were consistent with (or in contrast to) population norms. ${ }^{58}$ Finally, the use of these questionnaires was consistent with the way assessments are ordinarily conducted 
in the participating clinics, meaning that findings from this investigation would likely reflect those observed by clinical staff working in these settings who may act as potential gatekeepers for the initiation of lifestyle-related behavior change interventions.

\section{Procedure}

Clinic attendees were asked by a usual clinic staff member whether or not they would be interested in finding out about participation in the study. Those who were interested were subsequently contacted by a research assistant who provided a study information sheet, consent form, and questionnaire. This research assistant also addressed any questions potential participants had with regard to participation in the study. To maximize the response rate, potential respondents were instructed that they could either self-complete the survey then return it to a confidential sealed box located at the clinic administration desk at a subsequent appointment (or via post); read the responses over the telephone to a member of the research team who would call them 1 week after receiving the survey; or directly enter their responses onto a web-based version of the questionnaire via the internet (a web address was provided with the study information; additionally, four participants requested and were sent the link via email).

\section{Analysis}

Analyses were conducted using Stata/IC software (v 11.2; StataCorp LP, College Station, TX, USA). Descriptive statistics and figures were prepared to examine the age distribution, comorbid health conditions, BMI, and self-reported physical activity levels of the sample. Specifically, to examine the age distribution of respondents, a frequency histogram was prepared; the mean (and standard deviation [SD]) age was also calculated. In addition, a plot of the quantiles for patient age versus the quantiles of a normal distribution was also prepared (Q-Q plot), but this did not suggest that substantial deviation from a normal distribution was present (plot not displayed). For the purpose of subsequent descriptive analyses, the sample were categorized into a younger age group ( $<40$ years), middle age group (40-60 years), and older age group ( $>60$ years). The primary reasons for referral to the clinics and frequency of comorbid health conditions were tabulated for each age grouping. Frequency histograms were prepared to display the number of comorbid conditions present and BMI for each age group. BMIs were calculated as body mass in kilograms divided by the square of body height in meters and were categorized according to guidelines set out by the World Health Organization. ${ }^{59}$ Self-reported physical activity durations and intensities were presented in box plots.

To describe the health-related quality of life profile of this sample, frequency histograms were used to display the distribution of responses across the five health-related quality of life domains for each age group. Dolan's tariff system was applied to generate multi-attribute utility scores from the EQ-5D, where 0.00 represents death and 1.00 represents full health; health states considered worse than death are assigned a negative score. ${ }^{53}$ Dolan's preferencebased system was selected as it was derived from a society with similar values to that from which this sample was drawn; ${ }^{53}$ additionally, it has been widely used in psychometric investigations of the EQ-5D that have reported favorable findings. ${ }^{4-51,55-57}$ Mean (and SD) EQ-VAS and multi-attribute utility scores were determined for the three age groupings.

To investigate whether comorbidity, BMI, and selfreported physical activity (minutes of moderate intensity equivalent activity per week) were associated with patients overall health-related quality of life after adjusting for age, a generalized linear model was prepared. The generalized linear model (Gaussian family and identity link function) examined the association between the EQ-5D multi-attribute utility score (dependent variable) and the number of comorbid health conditions, BMI category, and (moderate) physical activity equivalent time (independent variables). Due to potential differences in the properties of the independent variables included in the generalized linear model, sensitivity of the model fit to selection of other potential family and link function combinations was performed. This was undertaken by substituting in all other potential family and link functions; similar model fits and the same significant associations were evident regardless of the combination of family and link function selected (only Gaussian family and identity link function presented). Prior to preparing the linear model, a correlation matrix was computed to examine any potential collinearity between the independent variables (as well as age as a potential confounder). All combinations of associations between the independent variables were weak at most (all rho <0.40). Age had a moderate association with number of comorbidities (rho $=0.44$ ) and weaker associations with physical activity time (rho $=-0.33$ ) and BMI (rho $=0.22$ ), supporting the inclusion of age as a potential confounding variable. To account for potential uncertainty in the nature of probability distribution for the observed coefficients from the generalized linear model, 95\% confidence 
intervals for the coefficients were generated using bootstrap resampling (2,000 replications, bias corrected and accelerated to adjust for any potential bias or skewness in the bootstrap distribution).

\section{Results}

A total of $224(76 \%)$ potential participants completed the survey. This included responses read to a research assistant over the telephone $(n=203,90.6 \%)$, those given online $(n=5$, $2.2 \%$ ), and those in hard copy returned to the patient's clinic $(n=16,7.1 \%)$. The primary reasons for referral to the participating clinics are displayed in Table 1. Back condition was the most frequently reported primary reason for referral across all ages (total $n=84,37.5 \%)$. Overall, 117 (52.2\%) respondents were male. The age of patients approximated a normal distribution (Figure 1), with the mean (SD) age being 53 (15) years. The youngest and oldest participants were 18 and 84, respectively.

Respondents reported a range of comorbid health conditions (Table 2), including a range of musculoskeletal disorders in addition to their primary reason for referral. Other common comorbid conditions included depression $(n=41,18.3 \%)$, hypertension $(n=40,17.9 \%)$, and diabetes $(n=39,17.4 \%)$. The majority of patients $(n=115,51.3 \%)$ reported two or more comorbidities in addition to their primary reason for attending the clinic. The minimum and maximum number of comorbidities reported was 0 and 14 , respectively. The number of comorbid conditions reported by respondents in each age group is presented in Figure 2, alongside the distribution of BMI for the sample. The overall pattern indicated increased comorbidity and obesity with age among this clinical sample. This was also consistent with the pattern of physical activity reported across the three age groups (Figure 3), with less physical activity time (particularly vigorous activity

Table I Primary reasons for respondent referrals to the participating clinics $(n=224)$

\begin{tabular}{|c|c|c|c|}
\hline \multirow[t]{3}{*}{ Reasons } & Age & Age & \multirow{3}{*}{$\begin{array}{l}\text { Age } \\
>60 \text { years, } \\
n(\%)\end{array}$} \\
\hline & \multicolumn{2}{|c|}{$<40$ years, $40-60$ years, } & \\
\hline & n (\%) & n (\%) & \\
\hline Back condition & $15(32.6)$ & $42(43.3)$ & $28(34.6)$ \\
\hline Shoulder condition & I3 (28.3) & $14(14.4)$ & $12(14.8)$ \\
\hline Knee condition & $3(6.5)$ & $10(10.3)$ & $6(7.4)$ \\
\hline Neck condition & $0(0.0)$ & $12(12.4)$ & $6(7.4)$ \\
\hline Elbow, wrist, or hand condition & $4(8.7)$ & $4(4.1)$ & $4(4.9)$ \\
\hline Ankle condition & $2(4.3)$ & $5(5.2)$ & $4(4.9)$ \\
\hline Hip condition & $3(6.5)$ & $2(2.1)$ & $3(3.7)$ \\
\hline Weight loss & $0(0.0)$ & $0(0.0)$ & I (I.2) \\
\hline Other condition & $6(13.0)$ & $8(8.2)$ & $17(2 \mid .0)$ \\
\hline
\end{tabular}

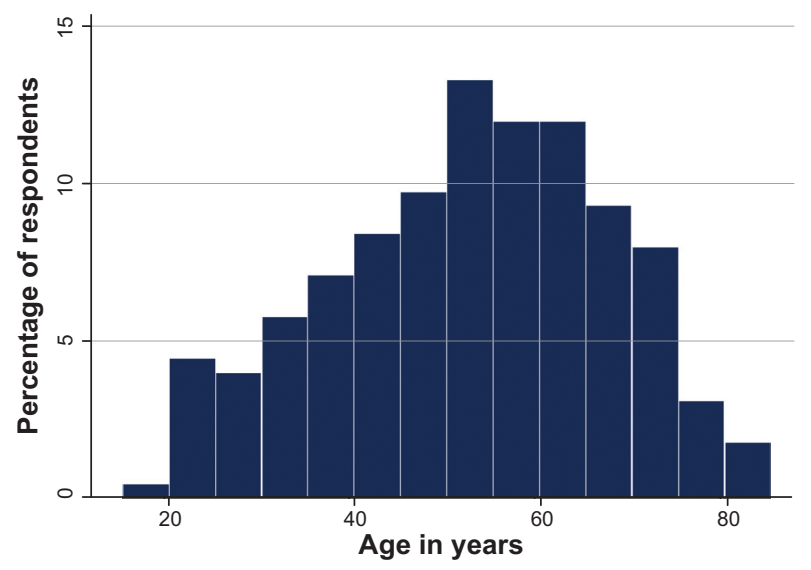

Figure I Age distribution of patients accessing ambulatory hospital clinics for musculoskeletal disorders.

time) reported by patients in the older age groups. The median (interquartile range) numbers of reported physical activity sessions of at least 10 minutes' duration were 8 (4-14) for respondents $<40$ years, 6 (3-9) for respondents aged 40-60 years, and 5 (3-9) for respondents aged $>60$ years. Overall, the amount of physical activity reported by $114(50.9 \%)$ respondents exceeded the minimum recommendations for health.

The mean and SD multi-attribute utility scores derived from the EQ-5D instrument $(0.562, \mathrm{SD}=0.298)$ and EQ-VAS score $(63.3, \mathrm{SD}=19.5)$ were not high relative to the possible scale range, indicating that impairments in health-related quality of life were prevalent in this clinical population. Health-related quality of life reported across the EQ-5D domains are displayed in Figure 4. Deficits were frequently reported across all five domains, with pain and discomfort the most frequently affected domain. A higher proportion of older patients reported problems with mobility than younger patients. Deficits in the domains of usual activities and depression or anxiety were present for substantial proportions of patients across each age group.

The linear model examining the association between patients' health-related quality of life (expressed as multiattribute utility) and their comorbid health conditions, BMI, and physical activity time (with age as a potential confounder) is displayed in Table 3. In summary, physical activity was positively associated and comorbidities were negatively associated with patients' health-related quality of life. BMI was not associated with health-related quality of life in this model. The coefficients from this model (Table 3 ) indicated that even modest differences in the physical activity and comorbidities variables were associated with a potential minimal clinically important difference of $0.03^{60}$ in 
Table 2 Frequency (percentage) of comorbid health conditions self-reported by respondents in addition to their primary reason for clinic attendance

\begin{tabular}{|c|c|c|c|}
\hline Conditions & $\begin{array}{l}\text { Age }<40 \text { years } \\
(n=46), n(\%)\end{array}$ & $\begin{array}{l}\text { Age } 40-59 \text { years } \\
(n=97), n(\%)\end{array}$ & $\begin{array}{l}\text { Age }>60 \text { years } \\
(n=81), n(\%)\end{array}$ \\
\hline \multicolumn{4}{|l|}{ Musculoskeletal disorders ${ }^{\mathrm{a}}$} \\
\hline Neck condition & $0(0.0)$ & $19(19.6)$ & $23(28.4)$ \\
\hline Osteoarthritis & $\mathrm{I}(2 . \mathrm{I})$ & $16(16.5)$ & $21(25.9)$ \\
\hline Knee condition & $\mathrm{I}(2.1)$ & $14(14.4)$ & $22(27.2)$ \\
\hline Shoulder condition & $0(0.0)$ & $15(15.5)$ & $19(23.5)$ \\
\hline Back condition & $\mathrm{I}(2.1)$ & $7(7.2)$ & $18(22.2)$ \\
\hline Hip condition & $\mathrm{I}(2.1)$ & II (II.3) & $13(16.0)$ \\
\hline Elbow, wrist, or hand condition & $3(6.4)$ & $6(6.2)$ & $9(I I . I)$ \\
\hline Osteoporosis & $\mathrm{I}(2 . \mathrm{I})$ & $4(4.1)$ & $13(16.1)$ \\
\hline Ankle condition & $0(0.0)$ & $5(5.2)$ & $9(I I . I)$ \\
\hline Other musculoskeletal condition & $6(12.8)$ & $13(13.4)$ & $15(18.5)$ \\
\hline Depression & $6(12.8)$ & $20(20.6)$ & $15(18.5)$ \\
\hline Hypertension & $0(0.0)$ & $18(18.6)$ & $22(27.2)$ \\
\hline Diabetes & $2(4.3)$ & $12(12.4)$ & $25(30.9)$ \\
\hline Heart condition & $\mathrm{I}(2.1)$ & $7(7.2)$ & $18(22.2)$ \\
\hline Eye problems & $\mathrm{I}(2.1)$ & $8(8.2)$ & $15(18.5)$ \\
\hline Asthma & $3(6.4)$ & $7(7.2)$ & $13(16.0)$ \\
\hline Cancer & $2(4.3)$ & $7(7.2)$ & $13(16.0)$ \\
\hline Obesity (self-reported) & $3(6.4)$ & $7(7.2)$ & II (13.6) \\
\hline Digestive problems & $0(0.0)$ & $3(3.1)$ & $7(8.6)$ \\
\hline Kidney disease & $0(0.0)$ & $5(5.2)$ & $4(4.9)$ \\
\hline Hay fever/allergies & $\mathrm{I}(2.1)$ & $3(3.1)$ & $4(4.9)$ \\
\hline Liver disease & $0(0.0)$ & $2(2.1)$ & $2(2.5)$ \\
\hline Fibromyalgia & $2(4.3)$ & $2(2.1)$ & $0(0.0)$ \\
\hline Epilepsy & I (2.I) & $2(2.1)$ & $\mathrm{I}(\mathrm{I} .2)$ \\
\hline Stroke & $0(0.0)$ & $\mathrm{I}(\mathrm{I} .0)$ & $3(3.7)$ \\
\hline Stomach ulcers & $0(0.0)$ & $\mathrm{I}(\mathrm{I} .0)$ & $2(2.5)$ \\
\hline Emphysema & $0(0.0)$ & $0(0.0)$ & $\mathrm{I}(\mathrm{I} .2)$ \\
\hline
\end{tabular}

Note: aMusculoskeletal disorder in addition to primary reason for attending clinic.

(health-related quality of life) utility score. For example, the coefficients in this model indicated that 2 hours of moderate physical activity per week, or 1 hour of vigorous physical activity per week, may be associated with a $>0.03$ higher utility score. Each comorbidity was associated with a 0.022 lower utility score.

\section{Discussion}

This investigation has suggested a large proportion of the patients accessing ambulatory clinics for musculoskeletal conditions were overweight or obese, had multiple chronic comorbid health conditions, and were physically inactive. The frequency of these undesirable clinical characteristics was higher among older patients than younger patients. Subsequently, patients frequently reported substantially impaired health-related quality of life associated with comorbidity and (lack of) physical activity. It is noteworthy that approximately one-half of the participants in this study self-reported physical activity levels that did not meet minimum recommended guidelines to experience health benefits associated with regular physical exercise. Given the other clinical characteristics of the sample (primary reasons for referral, BMI distribution, and comorbidities), and the propensity for some individuals to overestimate or overreport their physical activity when using self-reported measures, it is likely that this may be a conservative estimate of the proportion of patients who are insufficiently physically active for health benefits. ${ }^{61}$

The proportion of participants in this sample who were obese or severely obese was approximately double that of the wider Australian population. ${ }^{58}$ The high numbers of self-reported musculoskeletal disorders among this clinical group were expected. However, the rates of other chronic health conditions were concerning; these included frequent reports of depression, hypertension, and diabetes - conditions that may be ameliorated with physical activity. It is noteworthy that several of these common comorbid conditions are strong risk factors for the development of further severe health conditions including heart disease and stroke. ${ }^{62}$ The proportion of this sample that reported difficulty in health-related quality of life domains captured by the EQ-5D instrument were between two and seven times higher than 

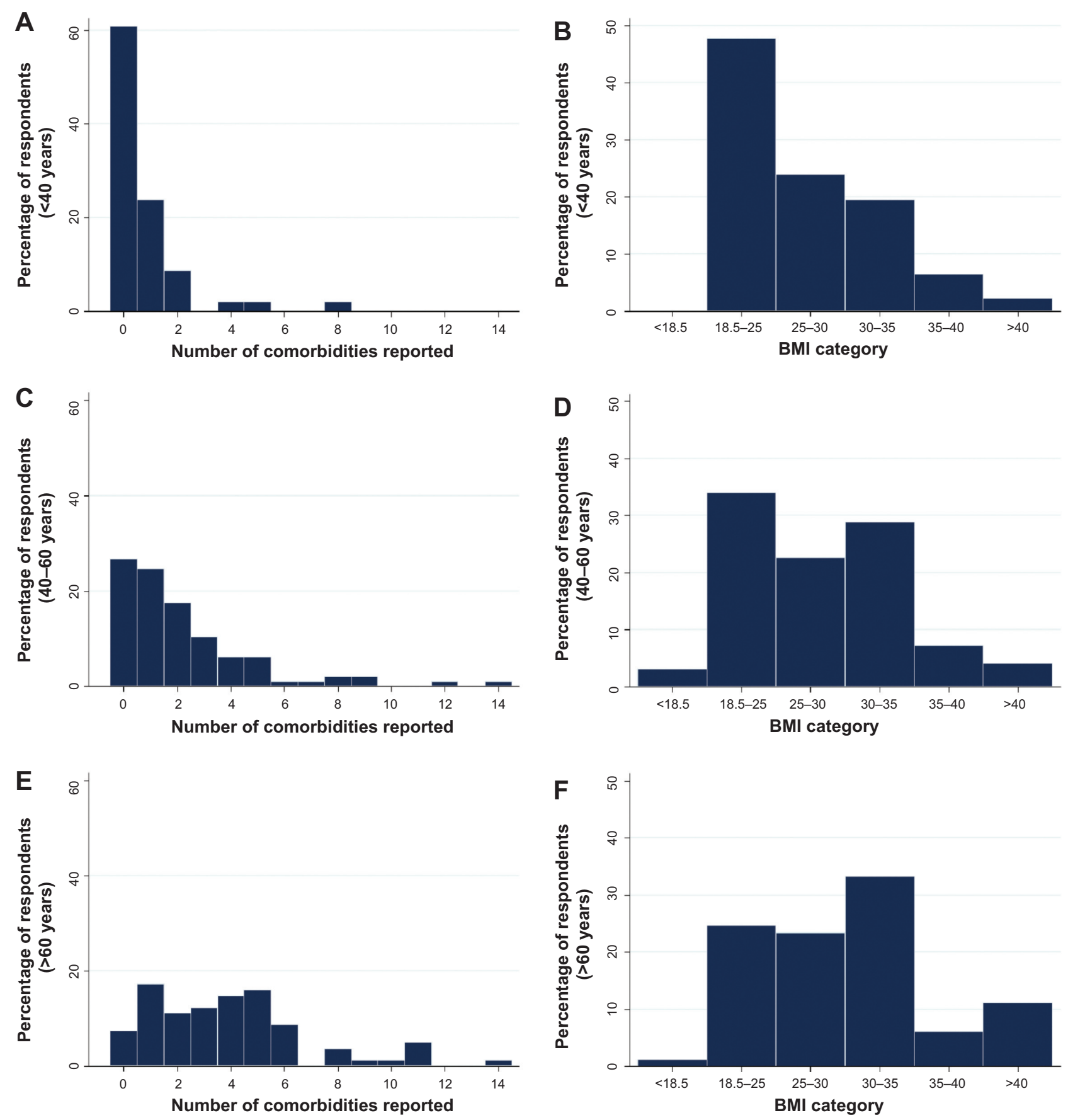

Figure 2 Number of comorbidities and percentage of respondents in each body mass index (BMI) category.

Notes: Number of comorbidities and BMl of patients aged $<40$ years (A and B), 40-60 years (C and D), and $>60$ years (E and F).

those reported by the wider population. ${ }^{63}$ While the purpose of this investigation was not to develop a comprehensive model of health-related quality of life correlates, the study did achieve an important objective in identifying that physical activity and number of comorbidities were associated with health-related quality of life, even after adjustment for age as a covariate.

These findings support further consideration of the potential integration of effective lifestyle behavior change interventions into clinical services, including general physical activity and dietary interventions. Assisting inactive and overweight patients to improve their health profile through better health-related behaviors may not only be beneficial for their presenting condition, but assist in the prevention or long-term management of other common chronic conditions that are present in this population. However, given that some types of physical activity may be inappropriate for people with certain musculoskeletal conditions, and that 

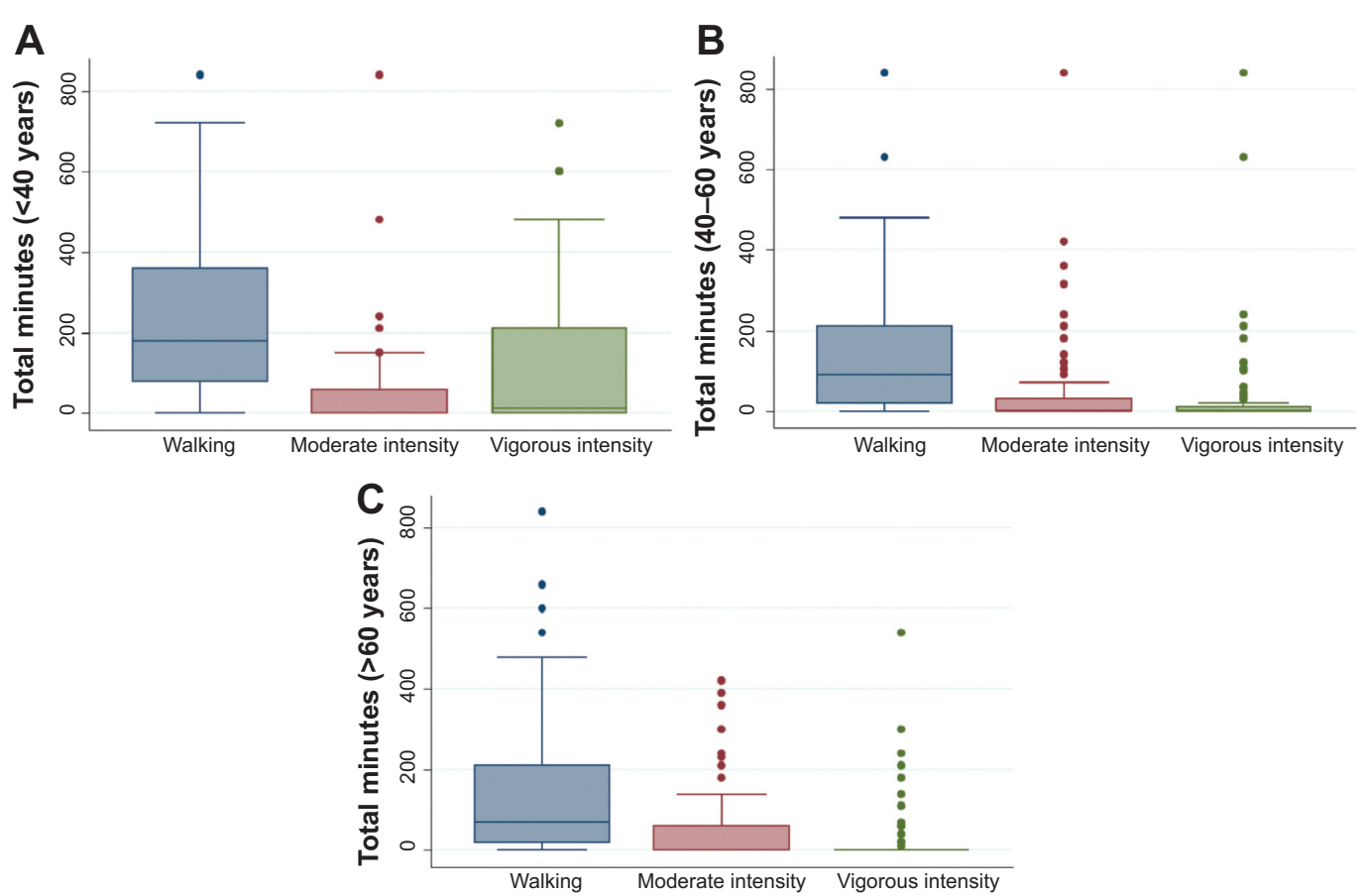

Figure 3 Physical activity among respondents.

Notes: Duration (in minutes) and type of physical activity reported in previous week by patients aged $<40$ years (A), 40-60 years (B), and $>60$ years (C).
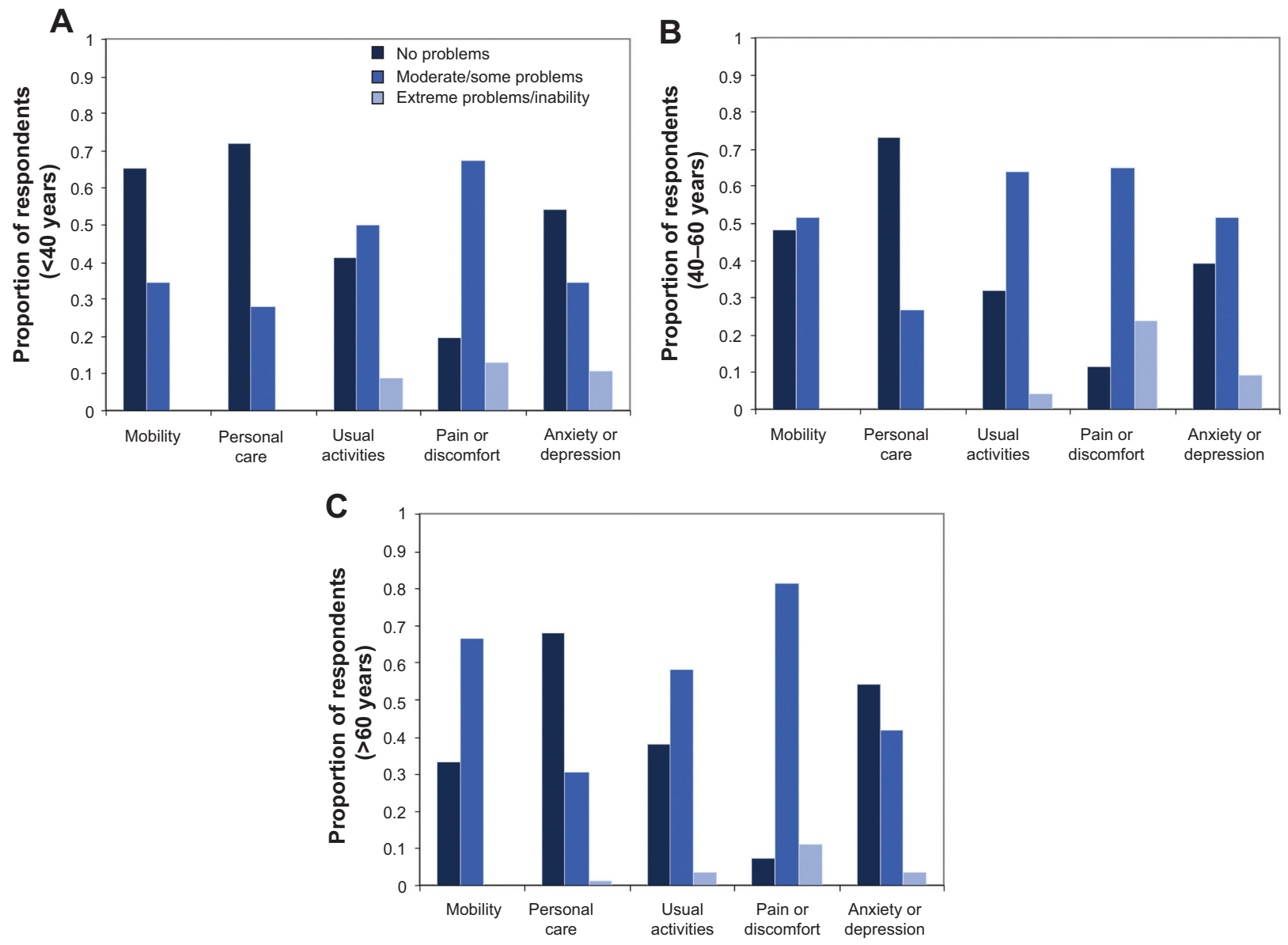

Figure 4 Health-related quality of life of respondents.

Notes: Health-related quality of life across EQ-5D domains ${ }^{46}$ for patients aged $<40$ years (A), $40-60$ years (B), and $>60$ years (C). 
Table 3 Summary of coefficients (and bootstrap-generated confidence intervals), $z$-scores, and $P$-values from the generalized linear model examining the association between multi-attribute utility and number of comorbidities, body mass index, physical activity time, and age

\begin{tabular}{|c|c|c|c|c|c|c|}
\hline \multirow[t]{2}{*}{ Dependent variable } & \multirow[t]{2}{*}{ Independent variables } & \multirow{2}{*}{$\begin{array}{l}\text { Observed } \\
\text { coefficient } \times 10^{2}\end{array}$} & \multicolumn{2}{|c|}{$95 \%$ confidence intervals } & \multirow[t]{2}{*}{ z-score } & \multirow[t]{2}{*}{$P$-value } \\
\hline & & & Lower & Upper & & \\
\hline \multirow[t]{4}{*}{ Multi-attribute utility } & Comorbidities & -2.200 & -3.812 & -0.587 & -2.67 & $<0.01$ \\
\hline & Body mass index & -1.089 & -4.400 & 2.222 & -0.64 & 0.52 \\
\hline & Physical activity time & 0.026 & 0.014 & 0.038 & 4.22 & $<0.001$ \\
\hline & Patient age & 0.320 & 0.059 & 0.576 & 2.41 & 0.02 \\
\hline
\end{tabular}

concurrent comorbidities (including depression) are prevalent in this clinical group, it is perhaps important that appropriately qualified health professionals have a direct role in the provision of advice and support for patients in this clinical setting. This may include the use of tailored physical activity programs suitable for the nature of the patient's condition and level of motivation.

The discrepancy between BMI and self-reported obesity as a health condition was also of interest. Only $22(9.8 \%)$ participants across all ages self-reported obesity as a health condition they had (Table 2). This is in contrast to the 94 (42.0\%) who reported their height and weight corresponding with a BMI value exceeding 30 . This discrepancy may be attributable to those with a BMI exceeding 30 either not considering themselves to be obese or not wanting to identify obesity as a health condition that they have. This underestimation of obesity may have implications both for the clinical management of musculoskeletal conditions associated with having excess body mass, as well as for motivation to make lifestyle-related changes, including to physical activity and dietary behaviors. This finding of self-underestimation of obesity is consistent with previous population-based investigations among adult and youth samples, ${ }^{64,65}$ and has previously been considered an impediment to associated nutritional lifestyle behavior change interventions for weight loss. ${ }^{65}$

This investigation had several methodological strengths as well as factors that limit the ability to extrapolate findings from this investigation. First, the target population for this investigation was specific to those accessing ambulatory hospital clinics for musculoskeletal disorders. It is possible that people with musculoskeletal disorders in dissimilar societies may not have responded in the same way as participants in this investigation. Second, offering participants the option for multiple modes of survey response may be considered both a strength and weakness of this investigation. Permitting multiple ways of returning survey responses may have contributed to the relatively high response rate ${ }^{66}$ however, the small proportion of the sample that chose to return their response via the internet or post box located in the clinic prohibited use of inferential statistics to confirm that no differences existed between the response return options. However, the use of standardized instruments within the survey that have demonstrated reliability using multiple administration modalities could be considered a strength. ${ }^{45,48-51}$ Third, the survey was self-reported. There is some evidence that people may overreport their physical activity level, as well as underreport their weight and overestimate their height for BMI calculations when completing self-report measures. ${ }^{61,67}$ So, while this self-report survey appropriately addressed the research objectives and potentially enhanced the response rate, the findings from this investigation regarding the presence of insufficient physical activity and proportion of the sample that were overweight or obese are likely to be a conservative estimate of the scale of these problems among this clinical population.

These findings have important implications for health care administrators, clinical leaders, practitioners, and researchers in this field. The finding of multiple health conditions, obesity, other musculoskeletal disorders, and impaired health-related quality of life is concerning, but not surprising, among this clinical group who were frequently physically inactive. Inactive patients who consume more dietary calories than they expend will likely continue to experience further negative consequences associated with physical inactivity and excessive caloric intake. They are more likely to develop additional chronic health conditions and die prematurely. ${ }^{27-33}$ Conversely, increasing their physical activity to recommended levels would likely promote a variety of health benefits, including reduced risk of death due to heart disease or stroke. ${ }^{29,30}$ In addition to reducing the risk of mortality, increasing physical activity levels among this group would likely result in reduced morbidity associated with the musculoskeletal disorders for which they are receiving treatment and other conditions associated with sedentary lifestyles..$^{28,31-35}$ Successfully promoting appropriate dietary intake could also yield a wide range of associated health benefits. ${ }^{68}$ 
The point of interaction between people with musculoskeletal disorders and health services offers an excellent opportunity to initiate transition to healthier lifestyles among this population. People currently accessing health services frequently only receive treatment for their primary diagnosis, with cursory attention given to lifestyle-related behaviors. ${ }^{69}$ The lack of provision of any personalized intervention, such as interventions addressing physical inactivity or dietary intake, is a missed opportunity. ${ }^{69}$ However, the presence of comorbidities, pain, and reduced mobility has implications for potential efforts to address the problem of physical inactivity in this population who may have difficulty undertaking conventional exercise. Unfortunately, there is currently a scarcity of research investigating lifestyle-related interventions specifically among people with musculoskeletal disorders, particularly among older adults. One proposed solution is to use the point of interaction between health professionals and inactive patients as a conduit to connect these patients with a targeted physical activity behavior change intervention that is suitable for their current health state and age. ${ }^{44}$ In the context of ambulatory musculoskeletal clinics, this is likely to involve guidance from the treating clinical experts regarding the types of physical activity suitable for each patient being referred for a physical activity intervention.

There are a number of priorities for future research to improve the health profile of patients of all ages with musculoskeletal disorders. Health professionals involved in the care of this clinical group may provide insight for the development of targeted lifestyle-related interventions and their integration into clinical settings. This insight may include the likely barriers and facilitators that patients may face when attempting to undertake physical activity, as well as pragmatic factors associated with the delivery of lifestyle interventions. ${ }^{44}$ Similarly, patients are also likely to be a valuable source of information regarding obstacles to altering their lifestyle and preferences for receiving support from health services. In addition to the development of interventions informed by patients and health professionals, the method by which these interventions are delivered is also worthy of consideration. ${ }^{44}$ For example, time pressures within existing clinical settings may necessitate the need for lifestyle interventions to be initiated within the clinical setting but with further support delivered remotely via the use of contemporary communication technologies. ${ }^{44}$ Successful behavior change interventions to improve the health profile of patients with musculoskeletal disorders will likely not only reduce patients' morbidity and mortality, but reduce the demand on health services and economic costs associated with future health care delivery.

\section{Conclusion}

Older patients were more frequently affected by undesirable clinical attributes of comorbidity, obesity, and physical inactivity than younger patients. These negative attributes were associated with impairment to patients' health-related quality of life. Findings from this investigation are compelling not only for the care of older patients accessing these clinical services, but for patients of all ages, with many younger patients also reporting negative clinical characteristics and impaired health-related quality of life. Potential integration of physical activity behavior change or other effective lifestyle interventions into models of care for patients with musculoskeletal disorders is worthy of further investigation.

\section{Disclosure}

The authors report no conflicts of interest in this work.

\section{References}

1. Côté P, van der Velde G, Cassidy JD, et al; Bone and Joint Decade 2000-2010 Task Force on Neck Pain and Its Associated Disorders. The burden and determinants of neck pain in workers: results of the Bone and Joint Decade 2000-2010 Task Force on Neck Pain and Its Associated Disorders. Spine (Phila Pa 1976). 2008;33(4 Suppl): S60-S74.

2. Parker L, Nazarian LN, Carrino JA, et al. Musculoskeletal imaging: medicare use, costs, and potential for cost substitution. J Am Coll Radiol. 2008;5(3):182-188.

3. Praemer A, Furner S, Rice DP; American Academy of Orthopaedic Surgeons. Musculoskeletal Conditions in the United States. Park Ridge, IL: American Academy of Orthopaedic Surgeons; 1992.

4. Stewart WF, Ricci JA, Chee E, Morganstein D, Lipton R. Lost productive time and cost due to common pain conditions in the US workforce. JAMA. 2003;290(18):2443-2454.

5. van Tulder MW, Koes BW, Bouter LM. A cost-of-illness study of back pain in The Netherlands. Pain. 1995;62(2):233-240.

6. Woolf AD, Pfleger B. Burden of major musculoskeletal conditions. Bull World Health Organ. 2003;81(9):646-656.

7. Yelin E. Cost of musculoskeletal diseases: impact of work disability and functional decline. J Rheumatol Suppl. 2003;68:8-11.

8. American Academy of Orthopaedic Surgeons. The Burden of Musculoskeletal Diseases in the United States: Prevalence, Societal and Economic Cost. 2nd ed. Park Ridge, IL: American Academy of Orthopaedic Surgeons; 2011.

9. Coyte PC, Asche CV, Croxford R, Chan B. The economic cost of musculoskeletal disorders in Canada. Arthritis Care Res. 1998;11(5): 315-325.

10. AIHW, Begg S, Vos T, Barker B, Stevenson C, Stanley L, Lopez A 2007. The burden of disease and injury in Australia 2003. Cat. no. PHE 82. Canberra: AIHW. Available from http://www.aihw.gov.au/ publication-detail/?id=6442467990. Accessed February 7, 2013.

11. Centers for Disease Control and Prevention (CDC). Prevalence of leisure-time and occupational physical activity among employed adults United States, 1990. MMWR Morb Mortal Wkly Rep. 2000;49(19): 420-424.

12. Boreham $\mathrm{C}$, Riddoch $\mathrm{C}$. The physical activity, fitness and health of children. J Sports Sci. 2001;19(12):915-929.

13. Cameron AJ, Dunstan DW, Owen N, et al. Health and mortality consequences of abdominal obesity: evidence from the AusDiab study. Med J Aust. 2009;191(4):202-208. 
14. Cameron AJ, Welborn TA, Zimmet PZ, et al. Overweight and obesity in Australia: the 1999-2000 Australian Diabetes, Obesity and Lifestyle Study (AusDiab). Med J Aust. 2003;178(9):427-432.

15. Cecchini M, Sassi F, Lauer JA, Lee YY, Guajardo-Barron V, Chisholm D. Tackling of unhealthy diets, physical inactivity, and obesity: health effects and cost-effectiveness. Lancet. 2010;376(9754): 1775-1784.

16. Dugan SA. Exercise for preventing childhood obesity. Phys Med Rehabil Clin N Am. 2008;19(2):205-216, vii.

17. Pan WH, Lee MS, Chuang SY, Lin YC, Fu ML. Obesity pandemic, correlated factors and guidelines to define, screen and manage obesity in Taiwan. Obes Rev. 2008;9 Suppl 1:22-31.

18. Trakas K, Oh PI, Singh S, Risebrough N, Shear NH. The health status of obese individuals in Canada. Int J Obes Relat Metab Disord. 2001;25(5): 662-668.

19. Wake M, Baur LA, Gerner B, et al. Outcomes and costs of primary care surveillance and intervention for overweight or obese children: the LEAP 2 randomised controlled trial. BMJ. 2009;339:b3308.

20. [No authors listed]. Obesity: preventing and managing the global epidemic. Report of a WHO consultation. World Health Organ Tech Rep Ser. 2000;894:i-xii, 1-253.

21. Centers for Disease Control and Prevention (CDC). State-specific prevalence of no leisure-time physical activity among adults with and without doctor-diagnosed arthritis - United States, 2009. MMWR Morb Mortal Wkly Rep. 2011;60(48):1641-1645.

22. Balboa-Castillo T, León-Muñoz LM, Graciani A, Rodríguez-Artalejo F, Guallar-Castillón P. Longitudinal association of physical activity and sedentary behavior during leisure time with health-related quality of life in community-dwelling older adults. Health Qual Life Outcomes. 2011;9:47.

23. Figueiredo Neto EM, Queluz TT, Freire BF. Physical activity and its association with quality of life in patients with osteoarthritis. Rev Bras Reumatol. 2011;51(6):544-549. English, Portuguese.

24. Li S, He H, Ding M, He C. The correlation of osteoporosis to clinical features: a study of 4382 female cases of a hospital cohort with musculoskeletal symptoms in southwest China. BMC Musculoskelet Disord. 2010;11:183.

25. McBeth J, Nicholl BI, Cordingley L, Davies KA, Macfarlane GJ. Chronic widespread pain predicts physical inactivity: results from the prospective EPIFUND study. Eur J Pain. 2010;14(9):972-979.

26. Morken T, Magerøy N, Moen BE. Physical activity is associated with a low prevalence of musculoskeletal disorders in the Royal Norwegian Navy: a cross sectional study. BMC Musculoskelet Disord. 2007;8:56

27. Global Recommendations on Physical Activity for Health. Geneva: World Health Organization; 2010. Available from http://whqlibdoc. who.int/publications/2010/9789241599979_eng.pdf. Accessed May $16,2013$.

28. Hu FB, Sigal RJ, Rich-Edwards JW, et al. Walking compared with vigorous physical activity and risk of type 2 diabetes in women: a prospective study. JAMA. 1999;282(15):1433-1439.

29. Hu FB, Stampfer MJ, Colditz GA, et al. Physical activity and risk of stroke in women. JAMA. 2000;283(22):2961-2967.

30. Manson JE, Hu FB, Rich-Edwards JW, et al. A prospective study of walking as compared with vigorous exercise in the prevention of coronary heart disease in women. N Engl J Med. 1999;341(9):650-658.

31. Bonnet F, Irving K, Terra JL, Nony P, Berthezène F, Moulin P. Depressive symptoms are associated with unhealthy lifestyles in hypertensive patients with the metabolic syndrome. J Hypertens. 2005;23(3): 611-617.

32. Booth FW, Gordon SE, Carlson CJ, Hamilton MT. Waging war on modern chronic diseases: primary prevention through exercise biology. J Appl Physiol (1985). 2000;88(2):774-787.

33. Colberg SR, Albright AL, Blissmer BJ, et al; American College of Sports Medicine; American Diabetes Association. Exercise and type 2 diabetes: American College of Sports Medicine and the American Diabetes Association: joint position statement. Exercise and type 2 diabetes. Med Sci Sports Exerc. 2010;42(12):2282-2303.
34. Warburton DE, Gledhill N, Quinney A. Musculoskeletal fitness and health. Can J Appl Physiol. 2001;26(2):217-237.

35. Warburton DE, Glendhill N, Quinney A. The effects of changes in musculoskeletal fitness on health. Can J Appl Physiol. 2001;26(2):161-216.

36. Chenoweth D, Leutzinger J. The economic cost of physical inactivity and excess weight in American adults. J Phys Act Health. 2006;3: $148-163$.

37. The Cost of Physical Inactivity: What is the Lack of Participation in Physical Activity Costing Australia? Medibank Private; 2007. Available from: http://www.medibank.com.au/Client/Documents/Pdfs/ pyhsical_inactivity.pdf. Accessed May 16, 2013.

38. Martinson BC, O’Connor PJ, Pronk NP. Physical inactivity and shortterm all-cause mortality in adults with chronic disease. Arch Intern Med. 2001;161(9):1173-1180.

39. Hill AM, Hoffmann T, McPhail S, et al. Evaluation of the sustained effect of inpatient falls prevention education and predictors of falls after hospital discharge - follow-up to a randomized controlled trial. J Gerontol A Biol Sci Med Sci. 2011;66(9):1001-1012.

40. Haines TP, Hill AM, Hill KD, et al. Cost effectiveness of patient education for the prevention of falls in hospital: economic evaluation from a randomized controlled trial. BMC Med. 2013;11:135.

41. Hill AM, Hoffmann T, McPhail S, et al. Factors associated with older patients' engagement in exercise after hospital discharge. Arch Phys Med Rehabil. 2011;92(9):1395-1403.

42. McPhail S, Beller E, Haines T. Physical function and health-related quality of life of older adults undergoing hospital rehabilitation: how strong is the association? J Am Geriatr Soc. 2010;58(12): 2435-2437.

43. McPhail SM, Dunstan J, Canning J, Haines TP. Life impact of ankle fractures: qualitative analysis of patient and clinician experiences. $B M C$ Musculoskelet Disord. 2012;13(1):224.

44. McPhail S, Schippers M. An evolving perspective on physical activity counselling by medical professionals. BMC Fam Pract. 2012;13(1): 31.

45. The Active Australia Survey: A Guide and Manual for Implementation, Analysis and Reporting. Canberra: Australian Institute of Health and Welfare; 2003. Available from http://www.aihw.gov.au/publicationdetail/?id=6442467449. Accessed October 26, 2011.

46. Rabin R, de Charro F. EQ-5D: a measure of health status from the EuroQol Group. Ann Med. 2001;33(5):337-343.

47. McPhail SM, Waite MC. Physical activity and health-related quality of life among physiotherapists: a cross sectional survey in an Australian hospital and health service. J Occup Med Toxicol. 2014;9(1):1.

48. McPhail S, Lane P, Russell T, et al. Telephone reliability of the Frenchay Activity Index and EQ-5D amongst older adults. Health Qual Life Outcomes. 2009;7:48.

49. Coons SJ, Rao S, Keininger DL, Hays RD. A comparative review of generic quality-of-life instruments. Pharmacoeconomics. 2000;17(1): 13-35.

50. Fransen M, Edmonds J. Reliability and validity of the EuroQol in patients with osteoarthritis of the knee. Rheumatology (Oxford). 1999; 38(9):807-813.

51. Hurst NP, Kind P, Ruta D, Hunter M, Stubbings A. Measuring healthrelated quality of life in rheumatoid arthritis: validity, responsiveness and reliability of EuroQol (EQ-5D). Br J Rheumatol. 1997;36(5): 551-559.

52. Obradovic M, Lal A, Liedgens H. Validity and responsiveness of EuroQol-5 dimension (EQ-5D) versus Short Form-6 dimension (SF-6D) questionnaire in chronic pain. Health Qual Life Outcomes. 2013; 11:110.

53. Dolan P. Modeling valuations for EuroQol health states. Med Care. 1997;35(11):1095-1108.

54. Dolan P, Roberts J. Modelling valuations for Eq-5d health states: an alternative model using differences in valuations. Med Care. 2002; 40(5): $442-446$.

55. König HH, Ulshöfer A, Gregor M, et al. Validation of the EuroQol questionnaire in patients with inflammatory bowel disease. Eur $J$ Gastroenterol Hepatol. 2002;14(11):1205-1215. 
56. Schweikert B, Hahmann H, Leidl R. Validation of the EuroQol questionnaire in cardiac rehabilitation. Heart. 2006;92(1):62-67.

57. Krabbe PF, Peerenboom L, Langenhoff BS, Ruers TJ. Responsiveness of the generic EQ-5D summary measure compared to the diseasespecific EORTC QLQ C-30. Qual Life Res. 2004;13(7):1247-1253.

58. Australian Bureau of Statistics. National Health Survey: Health Risk Factors. Canberra: Australian Bureau of Statistics; 2010. Available from http://www.abs.gov.au/AUSSTATS/abs@.nsf/ DetailsPage/4364.02007-2008\%20\%28Reissue\%29?OpenDocument. Accessed December 11, 2012.

59. [No authors listed]. Physical status: the use and interpretation of anthropometry. Report of a WHO Expert Committee. World Health Organ Tech Rep Ser. 1995;854:1-452.

60. Petrou S, Hockley C. An investigation into the empirical validity of the EQ-5D and SF-6D based on hypothetical preferences in a general population. Health Econ. 2005;14(11):1169-1189.

61. Montoye HJ, Kemper HCG, Saris WHM, Washburn RA. Measuring Physical Activity and Energy Expenditure. Champaign, IL: Human Kinetics; 1996.

62. Roger VL, Go AS, Lloyd-Jones DM, et al; American Heart Association Statistics Committee and Stroke Statistics Subcommittee. Heart disease and stroke statistics - 2011 update: a report from the American Heart Association. Circulation. 2011;123(4):e18-e209.
63. Viney R, Norman R, King MT, et al. Time trade-off derived EQ-5D weights for Australia. Value Health. 2011;14(6):928-936.

64. Goodman E, Hinden BR, Khandelwal S. Accuracy of teen and parental reports of obesity and body mass index. Pediatrics. 2000;106(1 Pt 1): $52-58$.

65. Kuchler F, Variyam J. Mistakes were made: misperception as a barrier to reducing overweight. Int J Obes Relat Metab Disord. 2003;27(7): 856-861.

66. Baruch Y. Response rates in academic studies - a comparative analysis. Human Relations. 1999;52(4):421-438

67. Jeffery RW. Bias in reported body weight as a function of education, occupation, health and weight concern. Addict Behav. 1996;21(2): 217-222.

68. Krauss RM, Eckel RH, Howard B, et al. AHA Dietary Guidelines: revision 2000: a statement for healthcare professionals from the Nutrition Committee of the American Heart Association. Circulation. 2000; 102(18):2284-2299.

69. Østbye T, Yarnall KS, Krause KM, Pollak KI, Gradison M, Michener JL. Is there time for management of patients with chronic diseases in primary care? Ann Fam Med. 2005;3(3):209-214.
Clinical Interventions in Aging

\section{Publish your work in this journal}

Clinical Interventions in Aging is an international, peer-reviewed journal focusing on evidence-based reports on the value or lack thereof of treatments intended to prevent or delay the onset of maladaptive correlates of aging in human beings. This journal is indexed on PubMed Central, MedLine,

\section{Dovepress}

CAS, Scopus and the Elsevier Bibliographic databases. The manuscript management system is completely online and includes a very quick and fair peer-review system, which is all easy to use. Visit http://www.dovepress. com/testimonials.php to read real quotes from published authors. 